\title{
(t)
}

ARTIGOS DE TEMAS LIVRES/

FREE THEME ARTICLES

\section{O DEBATE DA VIOLÊNCIA CONTRA CRIANÇAS E ADOLESCENTES PELO SERVIÇO SOCIAL}

The debate of violence against children and adolescents by Social Work

\section{Rosangela Oliveira Gonzaga de Almeida ${ }^{1}$}

\section{RESUMO}

O presente texto apresenta uma versão resumida de um capítulo inédito da minha dissertação de mestrado defendida recentemente sob o título A violência contra crianças e adolescentes numa perspectiva crítica contemporânea do Serviço Social. Apresento, portanto, a minha apropriação do objeto de estudo: a violência contra crianças e adolescentes e a sua relação com a lógica capitalista e as mediações que expressam a vida global contemporânea, com destaque à particularidade brasileira.

\section{PALAVRAS-CHAVE}

Violência contra crianças e adolescentes. Mediações. Serviço Social.

\footnotetext{
${ }^{1}$ Assistente Social, Mestre em Serviço Social (UFRJ, 2010). Assistente Social lotada no Conselho Tutelar da Criança e do Adolescentede Madureira (RJ). Tutora em Curso de Especialização de Gestão em Saúde pela UNIRIO. E-mail: <roogonzaga@uol.com.br>.
}

Temporalis, Brasilia (DF), ano 11, n.21, p.147-176, jan./jun. 2011. 


\section{ABSTRACT}

This paper presents an abridged version of a chapter of my unpublished dissertation defended recently under the title: The violence against children and adolescents from a critical perspective of contemporary social work. I therefore present my appropriation of the study object: violence against children and adolescents and its relationship with the capitalist reasoning and mediations that express contemporary global life, with special emphasis on Brazil.

\section{KEYWORDS}

Violence against children and adolescents. Mediation. Social Work.

Submetido em 30/04/2011

Aceito em 30/07/2011

\section{INTRODUÇÃO}

Impossível não associar ao capitalismo os rótulos da decadência, pauperismo, intolerância, violência, tirania e barbárie. Aquela fábrica criada para produzir mercadorias trouxe à humanidade uma incomensurável violência. A fábrica não somente fragmentou-se (BEHRING, 2008, p.166), na verdade explodiu.

O Serviço Social, através do resgate do método de investigação marxiano, define as mediações para entendimento da realidade social. São as mediações que possibilitam o alcance da totalidade do fenômeno (PONTES, 2002).

É a razão que garante o caráter inteligível dos fatos e estes são seus fundamentos. Os fatos são "[...] constituídos [...]”, “[...] constitutivos $[\ldots]$ " e "[...]constituintes $[\ldots]$ " de relações racionais, atrelados estão aos princípios de causalidade e contradições (GUERRA, 2005, p.43). 


\section{temporalis}

ALMEIDA, R. O. G. de. O DEBATE DA VIOLÊNCIA

\section{AS MEDIAÇÕES E O SERVIÇO SOCIAL}

A dinâmica societária imposta pelo capitalismo institui diferentes e complexas expressões sócio-humanas originadas na intensificação da exploração. Netto (2008, p.48) apresenta, enquanto problema teórico, a determinação concreta da “[...] relação entre as expressões emergentes e as de modalidades imperantes explorações [...]". Há a necessidade, de considerar, prossegue o referido autor, a "[...] complexa totalidade dos sistemas de mediações[...]" no qual se concretiza a contemporânea acumulação do capital. O desafio teórico pressupõe "[...] a pesquisa das diferencialidades histórico-culturais (que entrelaçam elementos de relações de classe, geracionais, de gênero e de etnia constituídos em formações sociais específicas) que se cruzam e tencionam na efetividade social $[\ldots]$..."

O neoliberalismo enquanto ideologia que apresenta proposições práticas cujos conceitos e argumentos reproduzem 0 conservadorismo político - interferindo periodicamente nas responsabilidades do Estado, o que Ihe garante a qualidade de "[...] estratégia eficiente de predominância ideológica conferindo aparente originalidade e força persuasiva [...]" (DRAIBE, 1993, p.88) - vem acentuando a violência sob a classe trabalhadora. $\mathrm{Na}$ prática o neoliberalismo traz uma nova forma de condução a ser operada sob a mão-de-obra dentro do contexto de gestão e controle de fluxos de produção e a introdução de novas tecnologias que imprime outra lógica de formação intelectiva: o desenvolvimento de competências relacionadas à capacidade lógico-abstrata de decodificar, calcular, programar e gerenciar processos. Isso fez com que um contingente viesse a ser empurrado para as atividades sem necessidade de habilidade e competências - o que reduz drasticamente os níveis de salários e que outra parte permanecesse no desemprego engrossando o

Temporalis, Brasilia (DF), ano 11, n.21, p.147-176, jan./jun. 2011. 


\section{temporalis}

ALMEIDA, R. O. G. de. O DEBATE DA VIOLÊNCIA

mercado informal ou que sequer tivesse a possibilidade de entrar no mercado de trabalho.Isso fez com que um contingente viesse a ser empurrado para as atividades sem necessidade de habilidade e competências - o que reduz drasticamente os níveis de salários e que outra parte permanecesse no desemprego engrossando o mercado informal ou que sequer tivesse a possibilidade de entrar no mercado de trabalho. O desdobramento óbvio é o agravamento da pobreza. A ação violenta engendrada pelo neoliberalismo no que tange ao trabalho resulta num distanciamento entre aqueles que estão empregados e os que se encontram desempregados ou não mais vão retornar ao mercado de trabalho. Essa ação violenta inerente à lógica engendrada pelo neoliberalismo é reproduzida no âmbito das demais relações; as crianças e adolescentes são a parte sem força de todo o contexto de relações da classe trabalhadora e consequentemente vítimas dessa violência.

Iamamoto; Carvalho (1986) afirma que no processo capitalista de produção e reprodução a classe trabalhadora incorpora e reproduz as ideias e representações regidas pela ideologia burguesa "[...] que expressam estas relações e as condições materiais em que se produzem, encobrindo o antagonismo que as permeia" (IAMAMOTO; CARVALHO, 1986, p.30). Muito embora a violência não expresse uma ideia dominante, ela funda uma forma de condução do sistema em prol do seu objetivo maior que é a acumulação.

A universalidade que atinge a violência propicia que as formas pelas quais se materializa sejam incorporadas e reproduzidas fundamentando as relações sociais inclusive aquelas que abrangem crianças e adolescentes. A sua extensão globalizada justifica a incorporação segundo uma suposta naturalização e banalização, uma forma legítima de relação entre sujeitos sociais. A analogia e a conexão entre violência inerente à lógica que na 


\section{temporalis}

\section{ALMEIDA, R. O. G. de. O DEBATE DA VIOLÊNCIA}

contemporaneidade atingiu uma dimensão sem precedentes e a violência contra crianças e adolescentes na sua particularidade é objeto da alienação do trabalho. Nessa expressão de violência há a reprodução social dos elementos constitutivos dos processos sociais de produção. E por isso optei por trabalhar com as categorias mercadoria e trabalho.

A mercadoria é uma coisa que com suas propriedades "[...] satisfaz necessidades humanas [...]" independentemente da sua natureza ou gênese, considerando-se pressupostos da vaidade, alimentares ou fantasiosos. A mercadoria enquanto coisa serve na sua utilidade, carrega qualidade e quantidade, é definida por propriedades. São fatos históricos "[...] a descoberta dos diferentes modos, as diferentes maneiras de usar as coisas e a invenção das medidas socialmente aceitas [...]" (MARX, 1989, p. 42), assim como, a crítica e a ação junto às práticas que ferem a moral socialmente constituída e o caráter disciplinador dos comportamentos. Na evolução da sociedade, que hoje assume a feição contemporânea,apresenta uma função social para a criança e a adolescência diferenciada se comparada a períodos anteriores.

O sentido moderno de criança é dado pela burguesia. A arte medieval não reconhecia a criança. É possível que até o século XII, esta fase da vida não tivesse lugar ou função social. Em períodos bastante anteriores à sociedade burguesa, mais especificamente até o século XIII, “[...] não existem crianças caracterizadas por uma expressão popular[...]” (ARIÈS, 2011, p.18). Há uma recusa na incorporação das crianças, da morfologia infantil pela arte segundo Ariès (2011), na quase totalidade das civilizações arcaicas. Tomando como referência esse mesmo autor, o século XIII demarca uma aproximação com "[...] sentimento moderno [...]" de criança. Nas fases destacadas por esse autor, conceber a criança, entre os séculos XIII e XVII, passa pela divindade, pela insignificância de sua

Temporalis, Brasilia (DF), ano 11, n.21, p.147-176, jan./jun. 2011. 
existência que Ihe é atribuída diante da ameaça de morte pelas inseguranças de sobrevivência à época, quando a mortalidade infantil consiste numa realidade e chega à sua incorporação nos álbuns de família. Paralelamente, tem-se a indistinção de gênero e idade - crianças são adultos em miniatura - e a inexistência da preservação do pudor infantil.

Naquilo que é particular à época, a representação da criança sozinha surge no século XVII - "[...] uma nova sensibilidade [...]" (ARIÈS, 2011, p. 25). A criança nua tornada convenção: “[...] algo que deve ser relacionado com um amplo movimento de interesse em favor da infância" (ARIÈS, 2011, p.26). É o século em que os retratos de família começam a incorporar as crianças.

A iconografia religiosa e a devoção no século XVII, que inspiraram a evolução do "[...] sentimento da infância [...]" pautado na simplicidade, fraqueza, santidade, suavidade e encanto são virtudes que acompanham a criança e a adolescência na contemporaneidade (ARIÈS, 2011). Essas virtudes estão presentes na subjetividade fantasiosa de quem objetiva adquirir uma mercadoria para consumo próprio descaracterizando o ser humano, estabelecendo uma relação entre coisas - fetiche da mercadoria, ou ainda quando se objetiva sensibilizar outrem. A centralidade atribuída à criança naquele século não corresponde à proteção tal qual entendemos hoje e sim significa a sua incorporação à família a partir da evolução do sentimento.

Ariès (2011) ao considerar a evolução do sentimento da família em relação à criança e a introdução da escola, resgata a condição de aprendiz a qual era submetida dentro de uma lógica que afastava as crianças de suas famílias; um hábito difundido no século XV em todas as condições sociais: “[...] a substituição da aprendizagem pela escola exprime também uma aproximação da família e das crianças e do 


\section{temporolis}

\section{ALMEIDA, R. O. G. de. O DEBATE DA VIOLÊNCIA}

sentimento da infância, outrora separados. A família concentrou-se na criança" (ARIÈS, 2011, p.159) - contudo, mantendo uma distinção entre gêneros: as crianças do sexo feminino somente tiveram acesso à escolaridade a partir dos séculos XVIII e XIX. No interior da evolução da escola, coube a prática legitimada de castigos físicos,assim como, esteve presente o viés moralizador e disciplinador aos quais as crianças eram submetidas.

A maneira como tais formas de conduzir a relação entre adultos e crianças chega à sociedade colonial brasileira - através da política do universalismo, conforme nos apresenta o autor Wallerstein (2007), no seu livro O universalismo europeu: a retórica do poder. A superioridade e o poder econômico de Portugal impôs regras de sociabilidade. A organização da sociedade brasileira a partir da escravatura demarca uma possível gênese para relações de violência estabelecida entre homens definindo um marco para as características do país. A processualidade histórica a partir daí se desdobra numa particularidade repleta de múltiplas determinações que coincide na cronologia histórica com o surgimento da ideologia social burguesa com suas peculiaridades unívocas.

O caráter misterioso da mercadoria - fetiche da mercadoria -se define a partir do fato de

[...] encobrir as características sociais do próprio trabalho dos homens, apresentando-as como características materiais e propriedades sociais inerentes aos produtos do trabalho; por ocultar, portanto, a relação social entre os trabalhos individuais dos produtores e o trabalho total, ao refleti-la como relação social existente, à margem deles, entre os produtosdo seu próprio trabalho $[\ldots]($ MARX, 1989, p. 81).

Temporalis, Brasilia (DF), ano 11, n.21, p.147-176, jan./jun. 2011. 
O desafio científico diz respeito a ultrapassarmos o fetiche da mercadoria. Karl Marx denomina fetichismos como: “[...] os produtos do cérebro humano parecem dotados de vida própria, figuras autônomas que mantêm relações entre si e com os seres humanos. É o que ocorre com os produtos da mão humana, no mundo das mercadorias[...]" (MARX, 1989, p. 81).

O trabalho demandado pela lógica capitalista define que haja o individuo disposto a vender a sua força de trabalho em troca de salário: uma sujeição invariavelmente repleta de violência. Essa violência é engendrada dentro de uma lógica que garante exclusivamente o lucro: são os mecanismos de exploração e espoliação inerentes à relação capital-trabalho. A relação entre aquele que vive da venda da sua força de trabalho e o capitalista acontece mediante um confronto hostil que se inicia com a definição de salário, em que um dos lados acumula todos os prejuízos. As perdas monetárias que materializam a exploração e a espoliação através do salário são acumuladas pela classe trabalhadora: são brutais e violentas. O trabalhador vende a sua força de trabalho em troca de um salário ao capitalista e junto a ele continua numa relação de subalternidade, servidão e violência. Essa relação é única, abrange a todos os trabalhadores; sua variável é a função a ocupar dentro da lógica da divisão social do trabalho, que define e quantifica o salário, o seu valor. A incorporação da categoria trabalho possibilita direcionar a minha argumentação para desvendar a violência contra crianças e adolescentes numa perspectiva de totalidade da sociedade que vive do trabalho.

O trabalhador se torna tanto mais pobre quanto mais riqueza produz, quanto mais a sua produção aumenta em poder e extensão. O trabalhador se torna uma mercadoria tão mais barata quanto mais mercadoria cria. Com a valorização do mundo das coisas [...] aumenta em proporção direta a desvalorização do 


\section{temporalis}

ALMEIDA, R. O. G. de. O DEBATE DA VIOLÊNCIA

mundo dos homens [...]. O trabalho não produz somente mercadorias; ele produz a si mesmo e ao trabalhador como uma mercadoria, e isto na medida em que produz, de fato, mercadorias em geral [...]. A efetivação do trabalho tanto aparece como desefetivação que o trabalhador é desefetivado até morrer de fome. A objetivação tanto aparece como perda do objeto que o trabalhador é despojado dos objetos mais necessários não somente à vida, mas também dos objetos do trabalho. Sim, o trabalho mesmo se torna um objeto, do qual o trabalhador só pode se apossar com maiores esforços e com as mais extraordinárias interrupções [...].O trabalhador encerra a sua vida no objeto; mas agora ele não pertence mais a ele, mas sim ao objeto[...] (MARX, 2008, p.80-81).

Para o entendimento das ações violentas contra crianças e adolescentes direciono a incorporação das categorias simples lucro, valor de troca e oferta associada à lógica da utilidade. As crianças e adolescentes são vítimas como se fossem coisas às quais podemos dispor, uma mercadoria, embutida de as suas características inerentes, descartável, utilizável e substituível. Incorporo também a fragilidade peculiar destas fases do desenvolvimento para a minha.

O Brasil demarca uma oferta expressa nos números para população de crianças e adolescentes. As relações violentas denunciam a simplificação das relações com as crianças e adolescentes- uma relação entre coisasaos quais se dimensiona o valor-de-uso e o valor-de-troca e se exprime a banalização quanto às medidas de proteção.

Segundo dados do IBGE - na Pesquisa Nacional por Amostra de Domicílios 1999/2009 -, a distribuição percentual da população de crianças e adolescentes em 2009 era 8,5\% entre as idades de 0 a 5 
anos; $15,8 \%$ entre as idades de 6 a 14 anos e 5,4\% entre as idades de 15 a 17 anos. A taxa de ocupação de crianças e adolescentes segundo grupos de idade no total das regiões metropolitanas brasileiras em 2009entre 10 e 15 anos era de 9,2\% e entre as idades de 16 e 17 anos de 32\% (IBGE, 2010).

Se observada a relação entre crianças e adolescentes de 10 a 17 anos de idade - por grupo de idade, total e respectiva distribuição percentual, por condição de atividade na semana de referência em 2008 -, segundo o IBGE (2009), na Pesquisa Nacional de Amostra de Domicílios 2008, chega-se aos seguintes dados no Brasil: a)dos que têm entre 10 a 15 anos, apenas 0,8\% trabalha;1,3\% cuida de afazeres domésticos; $1,4 \%$ não realiza nenhuma atividade; eb) dos que têm entre 16 e 17 anos 9,2\% trabalham; 6,6\% cuidam dos afazeres domésticos; 3,4\% não realizam nenhuma atividade. Num contexto numérico populacional de mais de 190 milhões de habitantes, segundo dados do Censo 2010, esses números são enormes (IBGE, 2011).

Segundo os dados produzidos pelo Inquérito Vigilância de Violências e Acidentes em Serviços Sentinelas de Urgências e Emergências (VIVA) - 2009 - levantamento previsto na Política Nacional de Redução na Mortalidade por Acidentes e Violências, política instituída pelo Ministério da Saúde (BRASIL, 2009), na sua última apresentação de resultados, de 8.766 notificações, nos municípios selecionados, do total de violência doméstica, sexual e outras formas de violência, 2.075 referiam-se a crianças entre 0 a 9 anos e 2.389 às idades de 10 a19 anos.

A partir da caracterização dos atendimentos relacionados a violências doméstica, sexual e outros tipos violências por sexo, nos municípios selecionados brasileiros, tendo como referência o ano 


\section{temporolis}

\section{ALMEIDA, R. O. G. de. O DEBATE DA VIOLÊNCIA}

de 2008 Vigilância de Violências e Acidentes (VIVA) 2008/2009 -, chega-se aos seguintes resultados:

\begin{tabular}{|c|c|c|c|c|c|c|}
\hline \multirow{2}{*}{ Características } & \multicolumn{2}{|c|}{$\begin{array}{l}\text { Masculino } \\
(\mathrm{n}=2.530)\end{array}$} & \multicolumn{2}{|c|}{$\begin{array}{l}\text { Feminino } \\
(\mathrm{n}=6.236)\end{array}$} & \multicolumn{2}{|c|}{$\begin{array}{c}\text { Total } \\
(\mathrm{n}=8.766)\end{array}$} \\
\hline & $\mathbf{N}$ & $\%$ & $\mathbf{N}$ & $\%$ & $\mathbf{N}$ & $\%$ \\
\hline \multicolumn{7}{|l|}{ Tipo de Violência } \\
\hline Física & 1648 & 65,1 & 3240 & 52,0 & 4888 & 55,8 \\
\hline \multirow{2}{*}{$\begin{array}{c}\text { Psicológica/moral } \\
\text { Negligência/abandono }\end{array}$} & 527 & 20,8 & 3087 & 49,5 & 3614 & 41,2 \\
\hline & 496 & 19,6 & 694 & 11,1 & 1190 & 13,6 \\
\hline Sexual & 351 & 13,9 & 2429 & 39,0 & 2780 & 31,7 \\
\hline Tráfico de seres humanos & 9 & 0,4 & 20 & 0,3 & 29 & 0,3 \\
\hline \multirow{3}{*}{$\begin{array}{l}\text { Financeira } \\
\text { Tortura } \\
\text { rabalho infantil }\end{array}$} & 55 & 2,2 & 135 & 2,2 & 190 & 2,2 \\
\hline & 24 & 0,9 & 101 & 1,6 & 125 & 1,4 \\
\hline & 10 & 0,4 & 12 & 0,2 & 22 & 0,3 \\
\hline Patrimonial & 2 & 0,1 & 24 & 0,4 & 26 & 0,3 \\
\hline
\end{tabular}

Fonte: Brasil (2009).

O ato de simplificar as relações coisificando-as segundo a lógica da produção e da reprodução deixa subjacente a alienação do trabalho e o ato de banalizar afasta o caráter da proteção inerente as poucas idades e enaltece a violação. Aqui são destacadas as violações: agredir, violentar ou usar. As violências contra crianças e adolescentes independem da classe social, pois elas acontecem no âmbito das relações sociais de produção e reprodução e não no espaço delimitado da pobreza.

Da maximização de lucros pelo capitalista que Engels ((01888) demarca enquanto o componente que distingue o emprego de violência na história, somada à apresentação por Sánchez Vázquez (1977) da violência enquanto inerente ao homem, lanni (2004) entende 
[...] o século XX, e entrando pelo século XXI, o que se verifica é uma revolução social permanente, subjacente às mais diversas formas de integração $e$ fragmentação, acomodação e contradição, sempre envolvendo classes e facções de classes, grupos étnicos, de gênero, religiosos e outros[...] (IANNI, 2004, p.16-17, grifos do autor).

A sociedade civil mundial (IANNI, 2004) configura-se a partir da fábrica global ou máquina global. A história se compõe de outras e novas guerras e revoluções e sem que se possa esquecer, de mais violência.

Não obstante, os acontecimentos são apreendidos como "[...] algo secundário [...]", aparentemente sem importância, como fatos isolados; a realidade é fragmentada, não havendo uma "[...] conexão com o curso da história [...]"; compartilha-se a " [...] ilusão [...]" de cada época(MARX; ENGELS, 1989, p.57).

O capitalismo sintetiza classes sociais, grupos sociais nos planos locais, nacionais, regionais e mundiais.

Acentuam-se as diversidades e desigualdades, em termos de formas de sociabilidade e jogos de forças sociais. As dimensões transnacionais do capital, tecnologia, força de trabalho, divisão do trabalho social, mercado, planejamento e violência, entre outras forças produtivas, intensificam e generalizam os processos de integração e fragmentação, em escala mundial [...]. É assim que se forma a sociedade civil mundial, compreendendo classes sociais e grupos sociais, bem como estruturas sociais de poder [...] (IANNI, 2004, p.31).

Na condução da Reforma do Estado - e o Serviço Social incluiria também, da Contrarreforma do Estado (BEHRING, 2003; 2008) no 


\section{temporolis}

\section{ALMEIDA, R. O. G. de. O DEBATE DA VIOLÊNCIA}

encaminhamento das diretrizes do neoliberalismo - está-se violentando a classe trabalhadora. Na mesma medida em que a economia nacional torna-se província do capitalismo global, a violência é incorporada na particularidade do Brasil, que corresponde a sua organização social, política, econômica, étnica, religiosa e ética a cada período da história.

A globalização do capitalismo enquanto define a dinâmica da produção e comercialização dita o processo civilizatório, produz novas formas de sociabilidade e jogos de forças sociais. Minha discussão está impregnada da concepção do quanto produção e comercialização globalizada atribuem à violência o caráter de globalização das suas expressões; do quanto a dimensão proporcional das ações violentas em grandeza conduzem a gravidade da violência de forma global. No entanto, transformo em objeto de estudo, dentro das necessidades óbvias de delimitação, a particularidade brasileira no que diz respeito à violência contra crianças e adolescentes.

Considero aqui uma sinalização de Lukács (1979) e também por Silva (2006) quanto aos resultados das ações dos sujeitos históricos, que são distintos e por vezes, contrários aos objetivos almejados nos atos de vontade dos homens.

Retornando às argumentações de Otavio lanni (2004), ele propõe que se repense o fazer político que expressa as mobilizações da classe trabalhadora.

Para que a sociedade civil possa recriar-se e dinamizar-se nesse novo patamar da história, tendose em conta os impasses e/ou horizontes que se abrem, pode ser fundamental que os indivíduos e as coletividades, os grupos e as classes que formam a 
ALMEIDA, R. O. G. de. O DEBATE DA VIOLÊNCIA

maioria do povo tomem consciência das rupturas que se acham em curso[...] (IANNI, 2004, p.59).

Pressuponho que a violência é uma expressão da questão social e esta tem implicações históricas, políticas, sociais e culturais que advêm dos antagonismos e contradições erguidos sob a exploração da classe operária no processo de produção da riqueza social. O caráter que distingue a violência na organização social que precedeu a ordem burguesa se refere às especificidades que a nova forma de sociabilidade impõe: a maximização dos lucros.

Todo o processo histórico que as mediações podem revelar decifra como a violência contra crianças e adolescentes permeiam as relações entre capital-trabalho e como no capitalismo globalizado e a partir da ideologia neoliberal apresenta configurações específicas. A produção e a reprodução da questão social adquirem perfis e expressões fundados na história e particularidade do cenário contemporâneo (IAMAMOTO; CARVALHO, 2004, p.10).

A configuração contemporânea da acumulação capitalista traz à tona novas expressões da questão social e necessita ser considerada a partir da complexa totalidade dos sistemas de mediações que a efetiva e das particularidades histórico-culturais e nacionais.A violência contra crianças e adolescentes a entendo enquanto uma expressão da questão social.

A questão social advém dos desdobramentos sócio-políticos da insatisfação da classe operária em relação às condições do trabalho. A minha leitura é que a gênese da violência contra crianças e adolescentes, na sua configuração contemporânea, está na ordem burguesa.Essa expressão da violência é engendrada pelo desenvolvimento das forças produtivas materiais: exploração e expropriação da classe trabalhadora. A “[...] questão social está 


\section{temporolis}

\section{ALMEIDA, R. O. G. de. O DEBATE DA VIOLÊNCIA}

elementarmente determinada pelo traço próprio e peculiar da relação capital-trabalho - a exploração" (NETTO, 2004, p.45).

Ao Serviço Social cabe empenhar-se na análise das singularidades das situações sociais que são apresentadas durante os atendimentos sociais na cotidianidade do exercício profissional. É importante que mantenha a sua atualização profissional mediante a presença da investigação social como parte da sua práxis.

A importância da investigação social na práxis profissional reside na efetivação da análise e síntese que conduz o profissional a não cair na armadilha da criminalização da pobreza para a qual induz o conservadorismo e o neoconservadorismo inerentes à ideologia burguesa.

Guerra (2009; 2010) propõe o que denomina ser imperativo ao Serviço Social:

[...] ousar saber para ousar transformar (GUERRA, 2009, p.715).

A dimensão investigativa tem que ser assumida como uma competência profissional e a pesquisa como indispensável à consolidação da área como produtora de conhecimento que tenha relevância social (GUERRA, 2010, p.734).

Para Wood (2006), há a necessidade de conhecermos as características do capitalismo; a exploração pelo sistema capitalista não considera as identidades, desigualdades e diferenças extraeconômicas, políticas ou jurídicas.

A extração da mais-valia dos trabalhadores assalariados acontece numa relação entre indivíduos formalmente iguais e livres e não pressupõe

Temporalis, Brasilia (DF), ano 11, n.21, p.147-176, jan./jun. 2011. 
diferenças de condição política ou jurídica. $\mathrm{Na}$ verdade, o capitalismo tem uma tendência positiva a solapar essas diferenças e a diluir identidades como gênero ou raça, pois o capital luta para absorver as pessoas no mercado de trabalho e para reduzi-las a unidades intercambiáves de trabalho, privadas de toda identidade específica (WOOD, 2006, p.229).

A condução do sistema acontece mediante as "[...] mistificações ideológicas [...]". A liberdade não é uma verdade, mas sim a maximização da produtividade e do lucro. São os:

[...] ideólogos capitalistas que nos asseguram que o capitalismo liberal é a última palavra em liberdade e democracia [...]. Parece haver uma ampla gama de relações sociais externas à estrutura de produção e exploração, que criam uma variedade de identidades sociais sem ligação imediata com a 'economia'. Nesse sentido, as identidades sociais parecem muito mais 'abertas'. Assim, é possível que a separação da economia pareça dar ao mundo externo a ela um alcance maior, uma liberdade maior [...]. Mas, na realidade, a economia do capitalismo invadiu e estreitou o domínio extra-econômico [...]. Praticamente não existe aspecto da vida na sociedade capitalista que não seja profundamente determinado pela lógica do mercado (WOOD, 2006, p.239).

Após as duas grandes Guerras Mundiais e a partir das transformações ocorridas na dinâmica do poder desde o início do século XX, a justificativa para as ações militares dos Estados Unidos, que assumiu o papel de potência mundial e que hoje possui a liderança bélica inquestionável, são pautadas na defesa dos direitos humanos. O poderio dos Estados Unidos, acompanhado do desenvolvimento da indústria bélica e ampliação das práticas terroristas pelo mundo e, ainda, a perda de importância e 


\title{
temporalis
}

\section{ALMEIDA, R. O. G. de. O DEBATE DA VIOLÊNCIA}

significado das negociações para encaminhamento das soluções diante de conflitos internacionais, vem ocasionando o aumento da violência de ordem planetária.

\begin{abstract}
[...] É a consagração da guerra 'infinita' como instrumento privilegiado de disciplinamento e controle da ordem mundial em mutação, completada pelos mecanismos de mercado da globalização capitalista e pelos dispositivos ideológicos culturais de sujeição (entre eles, os direitos humanos e a democracia [...] (GOMEZ, 2004, p.83).
\end{abstract}

Gomez (2004) ressalta que o direcionamento dado pelos Estados Unidos às estratégias de segurança constitui-se:

[...] por definição, o mais sério retrocesso do regime internacional dos direitos humanos dos últimos cinqüenta anos, um ataque direto às liberdades democráticas e um estímulo incessante à xenofobia e à intolerância cultural frente ao 'outro' ou 'diferente' que não encaixa ou simplesmente resiste aos padrões dominantes ocidentais [...] (GOMEZ, 2004, p.85).

Estou me referindo às questões de ordem macrossocial que impregnam, alteram e influem na sociabilidade dentro de um contexto histórico definido.

Raramente se questionam sobre a presença, importância e força das determinações externas, remanescentes do colonialismo e do imperialismo na dinâmica do globalismo ou neoliberalismo; precisamente na constituição, preservação e reiteração dessas 'características', 'limitações' ou 'distorções'. Abstraem traços, eventos e situações das suas reais condições histórico-sociais, políticoeconômicas, nas quais mesclam e articulam-se as condições internas e externas. Tanto abstraem, que

Temporalis, Brasilia (DF), ano 11, n.21, p.147-176, jan./jun. 2011. 
no limite as condições adversas em que vivem indivíduos e coletividades[...] o que implica na criminalização das vítimas responsáveis por suas condições adversas [...] (IANNI, 2009, p.203).

Já se concebe de forma indiscutível da força inerente à imagem na difusão de ideias, seja com a finalidade de aprendizagem ou para interferir na composição de novas formas de pensar ou agir. Interfere na construção e aperfeiçoamento do entendimento da realidade e do imaginário das individualidades, nos seus aspectos "[...] prosaico e revelador [...]", "[...] constitutivo e aterrador [...]". “[...] Os signos, símbolos, emblemas e alegorias, assim como os conceitos e as categorias, podem ser taquigrafias com as quais se articula, compreende, explica ou inventa a realidade, o outro e o eu, o eles e o nós, o bem e o mal" (IANNI, 2004, p.176).

A produção cultural é um negócio lucrativo que atrai investimentos do capital. A inserção da produção cultural na lógica de mercado conduz na sequência produções e mercado (captação de leitores, espectadores e audiências); mais e mais consumidores são acrescidos. Um tratamento igualitário concedido à "[...] indústria cultural [...]" "[...] sequiosa de novas produções [...]" e estas atravessando todos os limites na sua expansão territorial: impregna culturas e civilizações. Nesta lógica, segue a difusão da ideologia dominante. E consequentemente produz a alienação dos povos.

Esse o contexto em que nascem a imaginação, a produção, a difusão e o consumo de filmes, romances e programas de televisão sobre desastres e catástrofes, medo e terror, tumulto e desespero, aflição e pânico, violência e terrorismo, destruição e ruínas [...]. Assim se alimenta o imaginário de uns e outros, indivíduos e coletividades, em todo o mundo. Combinam-se o desastre e o pânico, o terrorismo e o medo, a destruição e a ruína, a engenhosidade e a 


\section{temporallis}

ALMEIDA, R. O. G. de. O DEBATE DA VIOLÊNCIA

produtividade, a performance e a lucratividade. Produzir o desastre, o terror e a destruição é produzir cultura e mercadoria, informação e entretenimento, lucro e mais-valia (IANNI, 2004, p.177-178).

Ianni (2004) destaca que a cultura da violência é utilizada na intenção de retratar e exorcizar a violência presente no âmbito das relações societárias onde há a sua exacerbação em nome de altos lucros. Em paralelo há o empenho em despolitizar multidões, não entendo que isso aconteça ao acaso. Estar-se-á a serviço de intenções perversas da lógica do capital. Despolitizar e alienar: assim as expressões da violência contra crianças e adolescentes ocupam cidadãos e os afasta qualquer possibilidade de apreensão política da dinâmica de sociabilidade que interessa a poucos de maneira vantajosa em detrimento de interesses que abarcam a maioria. É assim que grandes decisões sempre são definidas.

A cultura de massa no desenrolar do século XX e no ingresso do século XXI, mais acentuadamente a partir da introdução da imagem televisiva no interior das moradias da classe trabalhadora, adquire força, criatividade e espectacularidade (IANNI, 2004).

Sales (2009, p.36) ressalta a interferência dos processos “[...] plásticos sociais[...]" na formação das subjetividades contemporâneas dentro do contexto do que apontam os séculos XX e XXI para a "[...] multimedia [...]".

Trata-se, porém, de um cenário sócio-histórico ancorado na lógica da compressão, da miniaturização, da aceleração do tempo e da invisibilização de processos sociais, produtos de seus respectivos significados e custos socioeconômicos, com a subsequente virtualização da realidade e, para o bem e para o mal, das relações sociais... No reino das aparências da reificada sociedade de consumo,

Temporalis, Brasilia (DF), ano 11, n.21, p.147-176, jan./jun. 2011. 


\section{temporalis}

ALMEIDA, R. O. G. de. O DEBATE DA VIOLÊNCIA

tudo tende a assumir, portanto, um caráter supérfluo e descartável (SALES, 2009, p.36).

Há alguma aproximação entre violências nas guerras, nos ataques terroristas, na condução da lógica capitalista para acumulação, sob a lógica de encaixe de lucros, nas ditaduras na América Latina e no Brasil e por fim, na violência contra crianças e adolescentes: "[...] a violência adquire os refinamentos mais sofisticados possíveis, baseados na razão instrumental, traduzindo-se em técnicas de controle, administração, produção, alienação, brutalização" (IANNI, 2004, p.192).

E no que se refere às crianças e adolescentes, a cultura da violência se reveste na incorporação da naturalização e banalização da violência; a característica juvenil da população brasileira se configura na importação da lógica da calculabilidade numérica com que se tratam estes seres que demandam proteção.

Otávio lanni (2009) referindo-se à América Latina a partir do seu descobrimento a denomina enquanto um "[...] fragmento da cartografia mundial [...]”: “[...] um laboratório em constante ebulição, sem nunca configurar-se nem realizar-se plenamente[...]" (IANNI,2009,p.197) . Um território“[...] perpassa periodicamente um período pervasivo, estranho e penoso sentido de inquietação, incerteza, ilusão" (IANNI,2009, p. 218). Este território acumula na sua história "[...] formas de sociabilidade [...]" e " [...] jogos de forças sociais [...]" que expressam uma maneira peculiar de engendrar a dominação e a apropriação que se especificam configurando fases de violência. No Brasil, encontraremos configurações para violência que representavam os interesses de grupos presentes nos períodos que compreendem 0 patriarcalismo, o colonialismo, o imperialismo, o republicano e as ditaduras, análise que nos apresenta Silva (2004). 


\section{temporallis}

\section{ALMEIDA, R. O. G. de. O DEBATE DA VIOLÊNCIA}

O período de ditadura engendrado no Brasil iniciado na década de 60 denunciou o quanto grupos específicos estavam dispostos, em defesa de seus interesses, a utilizar o quanto deviolência fosse necessário. É inegável que a ditadura emplacou outra norma para configurar a violência contra seus opositores e inimigos. Ela atualizou outras formas de violência encaminhadas no período de fundação e consolidação da sociedade brasileira. A violência se materializou pela repressão, perseguição, tortura e morte institucionalizada sob o controle das Forças Armadas. A ditadura diluiu no interior da sociedade o pouco valor da vida, vulgarizou práticas violentas. Recorto algumas palavras de Ianni (2009) para definir tais violências:

Nesse labirinto, esconde-se a barbárie. Aos poucos, lenta, sub-reptícia ou de repente, explode a violência, destruindo coisas, gentes e idéias, realidades e ilusões. Tudo o que parecia plácido, fluindo no cotidiano de cada um e muitos, flutua sobre o que pode ser abismo, absurdo. A destruição germina sorrateira; ou irrompe abrupta, avassalando modos de ser. É como se a civilização fosse simultaneamente matriz de desencantamento e reencantamento, emancipação e alienação, esclarecimento e danação (IANNI, 2009, p.223).

O período da ditadura sendo uma das mediações que apresenta "[...] determinações objetivas da realidade [...]" é indiscutivelmente um período que demarca definitivamente a presença da violência do Estado segundo seus agentes legitimados a exercê-la na defesa de outros interesses que não os da população. A este período acresce-se o cenário internacional de guerras e terrorismo ao qual se assiste. Tais processos sociais a partir do seu "[...] núcleo inteligível [...]" com o dinamismo intrínseco ao movimento do real possibilitam através da razão a

Temporalis, Brasilia (DF), ano 11, n.21, p.147-176, jan./jun. 2011. 
sua apreensão e reconstrução. "É a regularidade dos fenômenos, processos e práticas sociais e sua historicidade que os tornam compreensíveis, permitindo à razão apreendê-los nas suas manifestações dinâmicas" (GUERRA, 2005, p.32).

Harvey (2005) avulta que os processos sociais definidos por Karl Marx para discorrer sobre o liberalismo - na sua versão atualizada o neoliberalismo - apresentam o quanto esta lógica produz níveis elevados de desigualdade social através de uma acumulação predatória, fraudulenta e violenta. "Todas as características da acumulação primitiva que Marx menciona permanecem fortemente presentes na geografia do capitalismo até nossos dias." (HARVEY, 2005, p.121). Essas características aprimoradas se apresentam na forma do sistema de crédito e capital financeiro e ainda, na acumulação por espoliação.

O Estado entraria nos processos de acumulação primitiva através da monopolização da violência e das definições da legalidade, com apoio e promoção de tais processos. "Tal como no passado, o poder do Estado é com freqüência usado para impor esses processos mesmo contrariando a vontade popular" (HARVEY, 2005, p.123).

O neoliberalismo pôde assim introduzir uma nova forma ideológica de conduzir os processos sociais com uma inexorável violência, às vezes, supostamente imperceptível e consentida no âmbito das relações mais simples, mas uma violência flagrante e inerente à lógica que o conduz. Nas palavras de Harvey (2005):

A mistura de coerção e consentimento no âmbito dessas atividades de barganha varia considerávelmente, sendo contudo possívelver agora com mais clareza como a hegemonia é construída por meio de mecanismos financeiros de modo a beneficiar $o$ 


\section{temporallis}

\section{ALMEIDA, R. O. G. de. O DEBATE DA VIOLÊNCIA}

hegemon e ao mesmo tempo deixar os Estados subalternos na via supostamente régia do desenvolvimento capitalista. O cordão umbilical que une acumulação por espoliação e reprodução expandida é o que lhe dão o capital financeiro e as instituições de crédito, como sempre com o apoio dos poderes do Estado. (HARVEY, 2005, p.126, grifo do autor).

O neoliberalismo é uma teoria que conduz as práticas de política econômica quanto à maximização das liberdades no mercado capitalista: criou um padrão de regulação global. Dentre seus desdobramentos perversos, num contexto de muita destruição para além das estruturas e poderes institucionais, Harvey (2007) destaca: as relações estruturais da força de trabalho, as relações sociais, as políticas de bem-estar social (na particularidade brasileira denomina-se a contra-reforma do Estado), os arranjos tecnológicos, os modos de vida, o pertencimento a terra, os hábitos efetivos, os modos de pensar etc.

À avaliação de Harvey (2007) que define a destruição criativa do neoliberalismo, acresço que esta se reproduz na violência contra crianças e adolescentes.

Se o principal sucesso do neoliberalismo não se encontra no que tange à geração de riquezas, mas sim à sua redistribuição, foi necessário descobrir meios para transferir ativos e redistribuir a riqueza e renda da massa da população em direção às classes altas, e dos países vulneráveis aos países mais ricos. (HARVEY, 2007, p.17-18).

O que resta à população sem alternativas de sobrevivência? Ela utiliza suas supostas pertenças, suas crianças e adolescentes, para também gerarem renda, das formas mais criativas possíveis, 
chegando ao crime em suas ações, negando todo e qualquer aparato legal que delega à família a responsabilidade de proteção.

A sociedade, fábrica da violência, em produção permanente dado ao incremento e sofisticação ascendentes de barbárie de dimensão globalizada, interfere e compõe ideias, subjetividades, sociabilidade, modos de vida.

O clima de barbárie em andamento, com disputas de forças antagônicas e dinâmica de poder em escala mundial, fez com que no Brasil o ano de 2007 se iniciasse com a chamada de ataque ao terror pela mídia, após várias situações de violências em que crianças e adolescentes foram vítimas ou autores de atos de extrema violência.

Houve uma manifestação contrária à instauração, desenvolvimento, generalização e naturalização do clima de barbárie protagonizado pela mídia. Esta focou as violências contra crianças e adolescentes considerados crimes, mas esqueceu-se de sinalizar que suas origens estão na condução histórica e legítima da violência na sociedade brasileira e no mundo, na corrupção e omissão do Estado, na gênese da situação de pobreza da população. As expressões de violências "[...] são vistas em si, em sua singularidade, como atos ou situações nos quais os agentes imediatos e as vítimas imediatas é que são considerados, lastimados, lembrados, culpados, glorificados" (IANNI, 2004, p.293).

É inegável que nessa forma de entender a violência e suas expressões houve um rompimento com qualquer possibilidade de estabelecer um diálogo com a teoria social de Karl Marx, de introduzir o debate dentro uma lógica critica, dialética, histórica e de totalidade. 


\section{temporalis}

ALMEIDA, R. O. G. de. O DEBATE DA VIOLÊNCIA

\section{CONCLUSÃO}

Generaliza-se a intolerância e o embrutecimento nas relações sociais. As pessoas tornaram-se rigorosamente violentas com uma performance humano-civilizada; a própria barbárie é um humano civilizado violento. A violência torna-se demarcada na lógica burguesa, funda as relações sociais. E na base da violência se fazem multiplicas e perpetuam-se as relações pela força da acumulação, sem qualquer possibilidade de crítica e transformação. Fica a fragmentação dos fatos violentos. Culpa-se e criminaliza-se, a ação se finda no veredicto. Contra crianças e adolescentes prevalecem as forças sob seres certamente indefensos dentro dessa lógica da reprodução das relações sociais de produção.

O Serviço Social ao ser convocado para intervir nas situações sociais onde há a constatação de violência contra crianças e adolescentes, invariavelmente existe uma expectativa técnico-operativa de quem toma tal iniciativa. Espera-se que, se constatada a situação de violência, se aponte os culpados, a culpabilização das famílias. A ação violenta e a negação de proteção não têm sua origem na família. A violência e a não proteção é conduzida pelo Estado e pelos interesses os quais defende dentro da ideologia neoliberal.

As famílias têm seu cotidiano estilhaçado pelos temas protagonizados pela relação genuinamente hostil e violenta entre capital-trabalho. $\mathrm{O}$ ato de culpabilizar as famílias representa fragmentação da realidade social, é simplificar o caminho de acionar aqueles a quem cabe a ação de encaminhar a redistribuição de renda.

A mídia cumpre dentro do processo de globalização do mercado o seu papel de conduzir os sujeitos sociais, uma lógica de reificação do consumo. Todos são induzidos a comprar indiscriminadamente.

Temporalis, Brasilia (DF), ano 11, n.21, p.147-176, jan./jun. 2011. 
Sem trabalho para todos, há aqueles que criam e recriam formas de acessar aquilo que objetivam consumir; crianças e adolescentes participam desse pacto familiar que os levam a situações de violência para conseguir o imediato, o dinheiro.

A condição de alienação na qual permanece a população a conduz a consumir, mesmo que lhe subtraiam o trabalho e todos os seus direitos sociais. Não há a presença da perspectiva de classe para possibilitar a crítica e a mobilização da população a priori. Este espaço continua em aberto.

"Sob o domínio do capital, a emancipação política é possível. Mas é impossível a emancipação humana. Quem a deseja deve desejar (e sobretudo, lutar) contra o domínio do capital" (NETTO, 2009, p.12). Uma lógica não somente perversa, é oponente à maioria da população que participa ocupando o lugar da parte explorada e expropriada, que aspira por liberdade. E somente mediante a liberdade há o alcance da emancipação humana.

\section{REFERÊNCIAS}

ARIÈS, P. História social da criança e da família. 2. ed. Rio de Janeiro: LTC, 2011.

BEHRING, E. R. Brasil em contrarreforma: desestruturação do Estado e perda de direitos. São Paulo: Cortez, 2003.

- Trabalho e Seguridade Social: o neoconservadorismo nas políticas sociais. In: BEHRING, E. R.; ALMEIDA, M. H. T. (Orgs.). Trabalho e Seguridade Social: percursos e dilemas. São Paulo: Cortez/UERJ, 2008. p.152-174. 


\section{temporolis}

ALMEIDA, R. O. G. de. O DEBATE DA VIOLÊNCIA

BRASIL. Secretaria de Vigilância em Saúde. Departamento de Análise de Situação de Saúde. Vigilância de Violências e Acidentes - VIVA - 2008 e 2009. Brasília (DF), 2009, 516p. Disponível em: <http://portal.saude.gov.br/portal/arquivos/pdf/viva_2008_2009_30_11_2 010.pdf >. Acesso em: 10 jun. 2011.

DRAIBE, S. As políticas sociais e o neoliberalismo; reflexões suscitadas pelas experiências latino-americanas. Revista USP, São Paulo, n. 17, mar/abr/mai. 1993, p.86-101.

ENGELS, F. O papel da violência na história. [S.n, @1888]. (Coleção Pensamento).

p.5-50.

GOMEZ, J. M. Direitos humanos, desenvolvimento e democracia na América Latina. Revista Praia Vermelha: Estudos de Política e Teoria Social, Rio de Janeiro, n.11, p.70-95, $2^{\circ}$ sem. 2004.

GUERRA, Y. A instrumentalidade do Serviço Social. 4. ed. São Paulo: Cortez, 2005.

. A dimensão investigativa no exercício profissional. In: CFESS; ABEPSS. Serviço Social: direitos sociais e competências profissionais. Brasília, 2009. p. 701-717.

- A formação profissional frente aos desafios da intervenção e das atuais configurações do ensino público, privado e a distância. Serviço Social e Sociedade, São Paulo, n. 104, p.715-736, 2010.

HARVEY, D. A acumulação via espoliação. In: HARVEY, David. O novo imperialismo. 2. ed. São Paulo: Loyola, 2005. p.115-148. 
ALMEIDA, R. O. G. de. O DEBATE DA VIOLÊNCIA

- O neoliberalismo como destruição criativa. Interfacehs: Revista de Gestão Integrada em Saúde do Trabalho e Meio Ambiente, São Paulo, v. 2, n. 4, p. 1-30, ago/2007. Disponível em: <http://www.revistaic.sp.senac.br/index.php/ITF/article/view/144>. Acesso em: 13 out. 2009.

IAMAMOTO, M. V.; CARVALHO, R. de. Relações sociais e Serviço Social no Brasil: esboço de uma intervenção históricometodológica. 5. ed. São Paulo: Cortez/Celats, 1986.

- Renovação e conservadorismo no Serviço Social: ensaios críticos. 7. ed. São Paulo: Cortez, 2004.

IANNI, O. Capitalismo, violência e terrorismo. Rio de Janeiro: Civilização Brasileira, 2004.

. Enigmas do pensamento. In: IAMAMOTO, M. V.; BEHRING, E. R. (Orgs.). Pensamento de Otávio Ianni: um balanco de sua contribuição à interpretação do Brasil. Rio de Janeiro: 7LETRAS, 2009. p. 195-244.

IBGE. Diretoria de Pesquisa. Coordenação de População e Indicadores Sociais. Síntese de Indicadores Sociais 2010: uma análise das condições de vida da população brasileira. Brasília, 2010. Disponível em: <http://www.ibge.gov.br>. Acesso em: 3 jan. 2011.

IBGE. Pesquisa Nacional por Amostra de Domicílios: síntese de indicadores 2008. Rio de Janeiro, 2009. Disponível em: <http://www.ibge.gov.br/home/estatistica/populacao/trabalhoeren dimento/pnad2008/sintesepnad2008.pdf>. Acesso em: 3 jan. 2011. 


\section{temporolis}

ALMEIDA, R. O. G. de. O DEBATE DA VIOLÊNCIA

. Sinopse do Censo 2010 Demográfico 2010. Rio de Janeiro, 2011. Disponível em: <http://www.ibge.gov.br/home/estatistica/populacao/censo2010/si nopse.pdf>. Acesso em: 3. jan. 2011.

LUKÁCS, G. Ontologia do ser social: princípios ontológicos fundamentais de Marx. São Paulo: Livraria Editora Ciências Humanas, 1979.

MARX, K. O capital: crítica da economia política: livro 1, v.1. 13.ed. Rio de Janeiro: Bertrand Brasil, 1989. $\overline{2008 .}$.

- Manuscritos econômicos-filosóficos. São Paulo: Boitempo, MARX, K. ; ENGELS, F. A ideologia alemã. 7. ed. São Paulo: Hucitec, 1989.

NETTO, J. P. A conjuntura brasileira: o serviço social posto à prova. Serviço Social e Sociedade, São Paulo, n.79, set. 2004, p. 5-26.

- Cinco notas a propósito da "questão social". Revista Temporalis, 2. ed, Brasília, n. 3, 2008, p. 41-49.

- Democracia e direitos humanos na América Latina: aportes necessários ao debate. In: FREIRE, S. de M. (Org.). Direitos humanos e questão social na América Latina. Rio de Janeiro: Gramma, 2009. p. 3-12.

PONTES, R. N. Mediação e Serviço Social: um estudo preliminar sobre a categoria teórica e sua apropriação pelo Serviço Social. 3. ed. São Paulo: Cortez, 2002. 


\section{tempordils}

ALMEIDA, R. O. G. de. O DEBATE DA VIOLÊNCIA

SALES, M. A. Mídia e questão social: o direito à informação como ética na resistência. In: SALES, M. A.; RUIZ, J. L. de S. (Orgs.). Mídia, questão social e Serviço Social. São Paulo: Cortez, 2009. p. 33-81.

SANCHEZ VÁZQUEZ, A. Praxis e violência. In: _. Filosofia da práxis. 2. ed. Rio de Janeiro: Paz e Terra, 1977. p. 373-404.

SILVA, J. F. S. da. "Justiceiros" e violência urbana. São Paulo: Cortez, 2004.

. Serviço Social e a violência estrutural: notas introdutórias. Serviço Social \& Realidade, Franca, v.15, n.1, p.159-174, 2006. Disponível em: <http://www.franca.unesp.br/ssrealidade/SSR_15n1.pdf $>$. Acesso em: 30 ago. 2011.

WALLERSTEIN, I. O universalismo europeu: a retórica do poder. São Paulo: Boitempo, 2007.

WOOD, E. M. Democracia contra capitalismo: a renovação do materialismo histórico. São Paulo: Boitempo, 2006. 